\title{
The Dimensions, Perfidy and Ramifications of Teenage Pregnancies with Examples from a Few Countries of the Globe. A Literature Review
}

\author{
Prof. S. M Kang'ethe \\ University of Fort Hare, Department of Social Work and Social Development \\ Private bag X1314, ALICE. 5700, South Africa \\ Email: skangethe@ufh.ac.za \\ Mr Festus Khayundi \\ Department: Library and Information science, P/B X1314, Alice \\ Email :fkhayundi@ufh.ac.za
}

Doi:10.5901/mjss.2014.v5n15p609

\begin{abstract}
Globally, teenage pregnancy appears to burgeon everyday despite global efforts to tackle it. The much desirable wind of modernization and development seems to wreak havoc to the institutions of adolescent sexual health. The aim of this paper is to raise debates, discourses on the underpinning of teenage pregnancy and suggest solutions or newer perspectives to tackle the quagmire. The paper has used a review of literature methodology. Findings indicate that teenage pregnancy is a result of adolescent sexuality, alcohol and use of drugs, ineffective use, or lack of contraceptives, sexual abuse, media influence, childhood environment, low levels of skills for sexual negotiation, gender power imbalances, sexual coercion and violence, poverty, low socioeconomic status, and peer pressure, among others; teenage pregnancy dooms the future of the teenagers and families have a pivotal role of controlling teenage pregnancies; and there is an inextricable relationship between teenage pregnancies and HIVIAIDS prevalence. The paper recommends countries to bolster the adolescent sexual reproductive health education; invoking religious tenets and mythology; embracing cultural sexual mores and taboos; and having political and societal goodwill to counter cultural attack especially from the western world.
\end{abstract}

Keywords: Poverty, STI/ HIVIAIDS, virginity testing, sexual mores, taboos, culture, resuscitate, going to the roots,

\section{Problem Statement}

In both developed and developing countries alike, the burgeoning cases of the phenomenon of teenage pregnancies calls for serious debates, discourses and research with the hope of coming up with solutions, or newer perspectives to tackle the quagmire. Teenage pregnancy has horrendous and pinching effects to the lives of the teenagers and by extension the countries they hail from. The phenomenon sacrifices their opportunity to exploit their future lives if not hindered by the pregnancy, jeopardizes their future schooling and usually drives them into a bottomless pit of poverty and despondency. Their self esteem, dignity and chances of getting decent marriages may be doomed. Therefore, taking opportunity to analyze and make a scholarly autopsy of possible underpinnings behind the phenomenon of teenage pregnancy remains a desirable eventuality that should be encouraged. This is to possibly come up with solutions or perspectives to either reduce or mitigate the phenomenon, or annihilate it altogether.

\section{Introduction and Background}

It is ironic that despite global investment and education on adolescent sexual reproductive health, teenage pregnancies continue to plague many countries, both developed and developing (Wikipedia, 2014). This poses serious perfidious aftermaths with horrendous and pinching ramifications. Incontrovertibly, teenage pregnancies, whether viewed from a social, psychological and emotional dimensions pose challenges bordering on ethical and moral dimensions, as well as compromise the individuals' dignity, self esteem and wreaks havoc to the societal moral fibre. Perhaps the gravest concern posed by teenage pregnancies today is its inextricable relationship with the prevalence of HIVIAIDS (Christofides et al., 2014) 
There are a lot of underpinnings behind the prevalence and the phenomenon of teenage pregnancy. However, the average age of first sexual intercourse, the high rate of pregnancies and the spread of sexually transmitted infections indicate the extent to which sex and sexuality have become major threats to adolescent health all over the world (Christofides et al., 2014; Brown, Greenberg, and Buerkel-Rothfuss, 1993). To this end, many countries, both developing and developed have been and are still engaged in devising programmes aimed at combating what has become a global challenge, more so because of its inextricable relationship with the prevalence of HIVIAIDS (Christofides et al., 2014; Ramphele, 2008; Barnett \& Whiteside, 2006). Teenage pregnancy, to say the least is perfidious with horrendous and pinching ramifications that need to be addressed timeously. It interplays with HIVIAIDS in that the latter is now recognized as the primary reproductive health concern for adolescents. Therefore, child bearing among teenagers remains a common social and public health concern worldwide (Dangal, 2006; Hogan, Sun \& Cornwell, 2000; Shaw, Lawlor \& Najman, 2006). The challenge, therefore, leaves researchers with assignments to come with plausible and sustainable approaches to reduce or mitigate the effects of teenage pregnancies. These researchers, who are also cultural architects, and are deeply concerned with exploring cultural ingredients from South Africa and Kenya are attempted to pull the whole world to investing their investigation into cultures in an endeavour to tap and harness their embedded social capital (Kang'ethe, 2013, 2014a). Such social capital, they believe should form platforms for recipe of the solutions to teenage pregnancies. Such recipes include reclaiming cultural practices such as virginity testing, embracing sexual mores and taboos and denouncing some of the western acquired cultures and replacing them with those that are afrocentric (Kang'ethe \& Duma, 2014; Kang'ethe, 2014a,b).

\section{Methodology}

This paper is has used a review of literature methodology. It is a discourse one, raising debates and discussions on the underpinnings behind teenage pregnancy and possible and plausible perspectives to address it. It has benefited from these researchers intuition especially from cultures, journals, books etc.

\section{The Perfidy and Ramifications of Teenage Pregnancies}

\subsection{Teenage pregnancy dooms the future of the teenagers}

Teenagers' lives and their respective countries stand to suffer a serious blow in the face of ever burgeoning cases of teenage pregnancies across many countries of the world, both developed and developing (Christofides et al., 2014). To say the least, teenagers stand to suffer the worst blow by the act, whether socially, psychologically, emotionally, or otherwise (Christofides et al., 2014). In the same vein, the countries of the teenagers who get pregnant may lose the resources they may have invested in such a youth and also lose out on the quality of life, or have the future of such a teenager jeopardized in various aspects of life. Teenage pregnancy has other hidden costs to the future of the victim. It has been established that in many cultures, teenage pregnancy affects the marriage prospects of young women. Studies in the United States of America (USA) reported that teen mothers are more likely to be single parents and if married they experience high divorce rates (Ashcraft and Young, 2006; UNFPA, 2007.) Teenage pregnancy is also associated with domestic violence and family disruptions. Studies from the Sub-Saharan Africa (SSA), USA and Europe have indicated that teenage mothers face high frequency of physical abuse. It tends to fit into the existing socially constructed gender imbalances by rendering young mothers more economically vulnerable (UNFPA, 2007).

\subsection{The role of families in controlling teenage pregnancies}

The pivotal place of families as institutions that can control and possibly discourage tendencies of teenage pregnancies cannot be overemphasized in any country of the globe (Kang'ethe and Gaseitsiwe, 2012). Gordon (1996) points out that the family has admittedly extensive impact on an adolescent's belief systems and values and hence on their subsequent behaviour. Consistent parental values have been recognized to influence later sexual debut by adolescents and is likely to decrease the risk of unintended pregnancies (Berglas, et al., 2003). For example, adolescents whose parents or family are clear about the value of delaying sex are less likely to have intercourse at an early age (Blum \& Rinehard, 1998; Miller et al., 2001). Undeniably, parental practices impact both the emotional and social development of adolescents. Parents or societies with set norms to enforce rules and monitor behaviour can positively impact sexual behaviour of adolescents (Kirby, 2002). 


\subsection{The aetiology and underpinnings of teenage pregnancy}

Perhaps identifying the causative agents of a behaviour is central to looking for possible and plausible solutions to the quagmire. Teenage pregnancy may come as a result of adolescent sexuality, alcohol and use of drugs, ineffective use or lack of contraceptives, sexual abuse, media influence, childhood environment, low levels of skills for sexual negotiation, gender power imbalances, sexual coercion and violence, poverty, low socioeconomic status, and peer pressure, among others (Wikipedia, 2013). Studies by individual researchers as well as those commissioned by organizations like the World Bank have also pointed out that the high incidence of premarital sexual activity may be attributed, inter alia, to the influence of the media. It was argued that although sexual content of the media can affect any age group, the adolescents are likely to be more vulnerable (Gruber and Greenberg, 2000, World Bank Press Release, 2013). Other aspects believed to precipitate premarital pregnancies associated with HIVIAID and STIs include urbanization, the impact of formal education, gender based inequality, economic deprivation, alcohol and substance abuse (Villarreal, 1998). Consequences of teenage or early childbearing impact on the status of one health, education, economic and social position (Breheny and Stephen, 2007; Hoffman, 2006; Kirby, 2007). In terms of health, teenage pregnancy may lead to elevated risks of maternal health; risks of obstetrics complications; low birth weight; high risk of infant mortality; and vulnerability to HIVIAIDS and STIs. Educational consequences include, inter alia, school dropout; school absenteeism; poor academic performance; low education attainment; poor cognitive development of children; and poor education outcome for children. Early childbearing may impact economic status leading to low family income; increased dependence ratio; and children are likely to be poor (Christofides et al., 2014). The social impact of early child bearing manifests itself through stigma and discrimination; less likely to be married; most likely to suffer abuse; lower supportive and stimulating home environment for children; possible increased behaviour problems among children; possible higher rates of imprisonment among male children; and children likely to give birth as teens (Christofides et al., 2014).

\subsection{Relationship between teenage pregnancies and HIVIAIDS}

Perhaps the most worrying factor pertaining to teenage pregnancies is the inextricable relationship between teenage pregnancy and the prevalence of HIVIAIDS (Christofides et al., 2014). This presents a grave challenge especially in African countries south of Sahara that although they constitute only a tenth of the global population are a refuge to nearly $80 \%$ of the global HIVIAIDS statistics (Kang'ethe 2010a; Ramphele, 2008; Treatment Action Campaign, 2007). Perhaps it is good to briefly indicate that since teenage pregnancy entails unprotected sex, viral transmission becomes a possible phenomenon in the sexual encounter. Studies have revealed that in the United States of America, nearly $50 \%$ of high school students had had sexual intercourse. 75 per 1000 adolescent girls aged between 15 and 17 in the USA became pregnant every year, this being seven times higher than rates recorded in any industrialised country (Brown, Greenberg, and Buerkel-Rothfuss, 1993). The rates were higher for Sub Saharan Africa where teenage pregnancy was at 143 per 1000 girls, and lowest in South Korea with 2.9 per 1000 girls. In South Africa, it was reported that there is a strong association between pregnancy and HIV among pregnant teenagers. Antenatal data showed that $12.9 \%$ of $15-19$ year old pregnant females were HIV positive (Department of Health (DOH), 2008).

\section{The Way Foward}

\subsection{Bolstering Adolescent sexual reproductive (ASR) health education}

These researchers believe that societies and communities especially in the developing part of the world have not had adequate education on reproductive sexual health (Christofides, et al., 2014). First, this could be because of the dearth of organizations dealing with this domain, and also many believe that this area is sacred and information pertaining to reproductive health is a private affair (Kang'ethe \& Rhakudu, 2010). With the dire consequences of unwanted pregnancies, there is recognition, both in the developed and developing world, of the great potential of the premarital sexual activity among the adolescents being a major cause of unplanned pregnancies and the apparent concomitant transmission of infections such as HIVIAIDS and other sexually transmitted infections. In the West, the emphasis has been placed on sex education being included in the school curriculum. In some countries, reproductive health programmes and services have been established by Non- Governmental Organizations (NGOs). For example in Botswana, reproduction sexual health education has been championed by Botswana Family Welfare Association (BOFWA) which has been getting its funding from international organizations such as UNICEF and WHO; as well as government funding. Unfortunately, the organization suffers dependency syndrome and dependence on volunteers for its 
operations. This has made it ineffective as a reproductive sexual health organization (Kang'ethe, 2010b). However, among all the sexual reproductive health bodies, the major emphasis of sex education is the promotion of sexual abstinence before marriage. The US government, for example, has supported the abstinence-only-until marriage programme since 1981 and has even extended it to some developing countries. According to McKeon (2006), there is need for a more comprehensive sex education programme than the one hitherto being supported and funded by the US government. Experts and organizations in support of a comprehensive sex education programme argue that such a programme seeks to assist the young people to make healthy decisions about sex and to adopt healthy sex behaviour. These groups have identified critical characteristics of highly effective sex education and HIVISTI prevention education programmes. Such programmes:

- Offer age and culturally appropriate sexual health information in a safe environment for participants

- Are developed in cooperation with members of the target community, especially young people

- Assist youth clarify their individual, family, and community values

- Assist youth develop skills in communication, refusal, and negotiation

- Provide medically accurate information about both abstinence and also contraception, including condoms

- Have clear goals for preventing HIV, other STIs, and/or teen pregnancy

- Focus on specific health behaviours related to the goals, with clear messages about these behaviours

- Address psychosocial risk and protective factors with activities to change each targeted risk and to promote each protective factor

- Respect community values and respond to community needs

- the activities as designed (McKeon, 2006)

\subsection{Invoking religious tenets and mythology}

These researchers believe that in the globe, religious practices remain the most important pillars of shaping the behaviour, enhancing and bolstering the morals, ethics and conventional mannerisms that make societies less stressful (Kang'ethe \& Rhakudu, 2010). To say the least, virtually all the major religious bodies in the world and their sacred literature, whether Christianity, Budhism, Islam, Sikhism and Hinduism have moral and ethical codes that are instrumental in shaping and maintaining moral and sexual chastity (Kang'ethe \& Rhakudu, 2010; MacArthur, 1997). To this end, premature pregnancy is always abhorred and condemned, and sometimes accompanied by immense social embarrassment, especially in Islamic faith where those who get pregnant illicitly can even be stoned to death. However, and despite these religious observations and norms, unplanned pregnancy among the adolescents has increasingly become an epidemic of perfidious and horrendous magnitude, and embracing pinching effects. According to available information from Wikipedia (Wikipedia, 2014), the fight against the problem ranges from the establishment of national and international programmes to the invoking of religious tenets and mythology (Kang'ethe, 2014a) Undeniably, many religious groups consider premarital sex to be morally objectionable. In most of the religions above, religious chastity is a virtue expected of faithful adherents. This entails abstinence from sex for the unmarried people. Many Christian denominations view sex in the context of marriage. Judaism forbids intercourse outside marriage. Similarly, Islam forbids intercourse outside marriage and marriage is strongly encouraged for those who become eligible for it (Kang'ethe \& Rhakudu, 2010).

\subsection{Embracing cultural sexual mores and taboos}

In these researchers' perspective, an array of cultural ingredients can be a panacea in shaping the behaviour, discipline and mannerisms of members of the society (Kang'ethe, 2014a). Perhaps this is why the call for Africans to consider going back to the roots as an approach to solve their own socio-economic problems has been listened by cultural architects and pragmatists with their third ears (Trevithick, 2005). Interpretably, this means or challenges Africans to consider their immense social capital espoused in their cultures and use it as a recipe for solutions besetting their countries (Kang'ethe, 2013). It can also be interpreted as a way of recognizing the Africans indigenous knowledge systems embedded in cultures, customs, traditions and generally people's ways of living (Kang'ethe, 2011). These researchers, therefore, are calling for most societies to go back and reclaim, reposition, , tap and harness the abandoned cultural practices such as sexual mores and taboos that made the societies refrain from illicit sexual engagement. These researchers who are making investigation into aspects of culture especially from Africa take this platform to ask governments and any authoritative bodies to consider advocating and lobbying to their societies to consider revisiting the above cultural 
practices to optimistically and hopefully give forth to girls as well as women who are ready to observe and embrace the tenets of chastity. This, undeniably will bring back countries' dignity as far as moral fibre is concerned (Kang'ethe, 2014a, c). As countries especially of Africa reel under the weight of HIVIAIDS, getting back to observe these cultural practices should be viewed as a panacea. Talking about Africa, Scott $(2009,83)$ stated that in order to fully understand the effects of HIVIAIDS in developing countries, particularly Africa, one must be able to take into account the political, economic, ecological, social and cultural factors that influence the representations of HIVIAIDS and the ways in which Africans perceive their health outlook. Essential to this understanding is awareness of the context in which decisions regarding health, health seeking-behaviour, and sexual behaviour are constructed.

\subsection{Political and societal will to counter cultural attack from the westerners}

Pivotally, It is still not easy, but it is doable to convince the people in the society to go back to their cultures, especially those that promise sexual chastity and a restoration of ethical and moral fibre (Kang'ethe, 2014a,c; Afolayan, 2004). This is because many countries especially of Africa were duped to abandon their cultures and follow those of the western world (Kang'ethe, 2009). However, following western cultures brought a barrage of social challenges and stresses that the western cultures could not solve. The Africans, in particular never deciphered that the westerners wanted Africans to be permanent slaves who would follow dogmatically the tune and the beat that the westerners wanted played. These researchers informed by the Swahili proverb that "mwacha mila ni mtumwa" (he/she who abandons his/her culture is like a slave), takes this opportunity to challenge countries that left their cultures to consider reclaiming them back and use them as vehicles of socio-economic development (Kitula, 2008). This is through starting to practice those cultural practices. These researchers need to pat the South African Zulu King, Goodwill Zwelithini for urging his Zulu people to reclaim and start practising virginity testing (Kang'ethe, 2014c). This therefore means that good will from authoritative personalities and governments are critical if people will easily find "sense in getting back to the roots" (Kang'ethe 2014c). These researchers challenge especially the African governments to strongly fund ministries concerned with cultures so that the process of campaigning and convincing people of the dire need to reclaim back desirable cultures is critical and long overdue.

\section{Conclusion}

Governments, NGOs, private bodies and individuals making up the societies in different countries need to pull their dagger to fight the horrendous and pinching effects of teenage pregnancies. The inextricable relationship between teenage pregnancies and the prevalence of HIVIAIDS especially in Africa has exacerbated the need for such recourse. Because apparently the environment of human rights as presented by the western countries has miserably failed the developing countries in tackling the challenges presented by teenage pregnancies, turning to embrace, tap and harness ingredients of cultures that proved to work before the advent of colonialism needs to be reverted to. Perceptibly, cultures especially in African countries can form plausible and sustainable approaches to the problem of teenage pregnancies. This therefore requires African countries to reclaim, reposition and resuscitate all the cultural ingredients that have in the past ensured chastity was maintained and strengthened.

\section{References}

Afolayan, F. ( 2004). Culture and Customs of South Africa. Westport, Connecticut: Greenwood Press Ashcraft, A \& Land, K (2006). Consequences of teenage childbearing. Available at http://ssrn.com.

Berglas, N., Brindis, C. \& Cohen, J. ( 2003). Adolescent pregnancy and child bearing in California. Available at http://www.library.ca/gov/crb/bdf. Accessed February 2014.

Barnett, T. \& Whiteside, A. (2002). AIDS in the Twenty-First Century. Disease and Globalization. Hampshire: Palgrave Macmillan

Blum, R.W. \& Rinehard, P.M (1998). Reducing the Risk: Connections that make a difference in the lives of youth. Center for Adolescent Health and Development, University of Minnesota. Minneapolis, MN

Breheny, M \& Stephens, C. (2007). Individual responsibility and social constraint: the construction of teenage on social scientific research. Culture, Health and Sexuality. Vol. 9, 336-346.

Brown, J.D, Greenberg, B.S, \& Buerkel-Rothfuss, N.L (1993). Mass Media, Sex and Sexuality. Adolescent Medicine Vol. 4 (3) Pp 511526

Christofides, N.J. et al. Journal of the International AIDS Society 2014, 17:18585 http://www.jiasociety.org/index.php /jias/article/view/18585 | http://dx.doi.org/10.7448//AS.17.1.18585

Dangal, G. (2006). Teenage pregnancy: complexities and challenges. Journal of Nepal Medical Association. Vol. 45, 262-272. 
Department of Health (2008). The National HIV and Syphilis prevalence survey South Africa 2007. Pretoria.

Gordon, C.P. (1996). Adolescent decision making: a broadly based theory and its application to prevention of early pregnancy. Adolescence Vol. 31, 561-584.

Gruber, E., \& Greenberg, J.W. (2000). Adolescent sexuality and the media: a review of current knowledge and implications. Available at www.ncbi.n/m.nih/gov/pmc/articles. Accessed February 2014.

Hoffman, S. (2006). By numbers: the public costs of teen childbearing. Available at http://www.thenationalcampaign.org/resources/pdf/ Accessed March 2014

Hogan, D.P, Sun, R. \& Cornwell, G.T. (2000) Sexual and fertility behaviors of American females aged 15-19 years: 1985, 1990, and 1995. American Journal of public health Vol. 90 (9) Pp 1421-1425.

Kang'ethe, S.M. (2009). Traditional healers as caregivers to HIVIAID patients. Sahara Journal. Vol. 6 (2). September, 2009. Pp.83-91.

Kang'ethe, S.M (2010a). The perfidious experiences of men as palliative caregivers of people living with HIVIAIDS and other terminal illnesses in Botswana. Indian Journal of Palliative Care. Sep-Dec 2010/Vol-16/lssue-3. Pp 159-164.

Kang'ethe, S.M (2010b). Evaluation of the support to care giving by local Non Governmental Organizations (NGOs) support in the Kanye care programme, Botswana. Maatskaplike 2010; 46, 2 : Pp209-223.

Kang'ethe, S.M (2011). Evidences of indigenous knowledge systems driving care giving in care programmes in Botswana. Fort Hare Papers. Vol 18, 2011. Pp 5-15.

Kang'ethe, S.M \& Rhakudu, M. (2010). Religious Education book for form 2. Heinemann Publishers, Gaborone.

Kang'ethe, S.M. \& Gaseitsiwe, B. (2012).Religious Education. Form Three. Botsalano Publishers. Gaborone

Kang'ethe, SM (2013.) The panacea and perfidy of cultural rites of circumcision in African countries: Examples from Kenya, Botswana, and South Africa. EASSRR Journal, Vol. xxix, No. 1, P.107-123.

Kang'ethe S.M 2014a. The panacea and perfidy of culture as a platform of behaviour change with examples from Botswana and South Africa. In the press of Mediterranean journal of social sciences, India

Kang'ethe, S.M (2014b). The need to resuscitate the cultural rite of virginity testing as a tool to strengthen the campaign against HIVIAIDS and moral decadence in South African region. Mediterranean Journal of Social Sciences. Vol5 No 8. Page 476-481

Kang'ethe, SM (2014c) Repositioning , Reclaiming and Rejuvenating the Niche of Traditional Practitioners in the face of Modernization in selected African Countries. Studies on Ethno-Medicine , India.

Kang'ethe, S.M \& Duma, V. (2014). Exploring Dimensions of Post -Apartheid Xenophobic Sentiments Towards African Immigrants in South Africa. Insight on African, India 5 ,2 (2013): 157-168

Kirby, D. ( 2002) Antecedents of adolescent initiation sex, contraceptive use and pregnancy. American Journal of Health Behaviour Vol. 26 Pp 473-485.

Kirby, D. (2007) Emerging answers 2007: research findings on programs to reduce teen pregnancy and sexually transmitted diseases. Washington, DC

Kitula, K (2008). Kamusi ya methali za Kiswahili. East African Educational Publishers. Nairobi

MacArthur, J. 1997. MacArthur Study Bible. Thomas-Nelson. Amazon, USA.

Mckeon, D. (2006). Advocate for Youth. Available at http://www.advocatesforyouth.org/publication-450. Accessed March 2014.

Miller, B.C, Benson, B. \& Galbraith, K.A (2001). Family relationships and adolescent pregnancy risk: a research synthesis. Development Review Vol. 21 Pp 1-38

Ramphele, M. (2008). Laying ghosts to Rest. Dilemmas of the Transformations in South Africa. Capetown: Tafelberg

Scott, S. ( 2009). HIVIAIDS: Understanding socio-cultural factors and their influence on sexual behaviour and decision making in Africa. Journal of the Manitoba Anthropology Students' Association. Vol. 28, 83-93.

Shaw, M., Lawlor, D.A, \& Najman, J.M (2006) Teenage children of teenage mothers, psychological, behavioural, and health outcomes from an Australian prospective longitudinal study. Social Science and Medicine Vol.62 Pp 2526-2539.

TAC (Treatment Action Campaign) 2007. 'Government Leadership on HIVIAIDS Irerevocably Defeats Denialism!Implement a New Credible Plan with Clear Targets!'Available at http://www.tac.org.za/ AIDSDEnialismlsDead.html. (Accessed on 22nd February 2014).

Trevithick, P. (2005). Social Work Skills and Knowledge. A practice Handbook. Open University Press, Maidenhead, England.

UNFPA (2007). Giving girls today and tomorrow: Breaking the cycle of adolescent pregnancy. Available at http://www.unfpa.org. Retrieved March 2014.

Villarreal, M. (1998) Adolescent fertility: sociocultural issues and programme implications. FAO. Geneva.

Wikipedia (2013) Teenage pregnancy. Available at http://en.wikipedia.org/wiki/Teenage_pregnancy. Accessed December 2013.

Wikipedia (2014) Abstinence-only sex education. Available at http://en.wikipedia.org/wiki/sex abstinence. Accessed March 2014.

World Bank Press Release (2013). Risky behaviours constitute growing threats to global health. Available at http://www.worldbank.org/en/news/press. Accessed 20 March 2014. 